\title{
Editorial
}

\section{Exploring serendipitous dialogue}

\section{Emma Weitkamp}

\begin{abstract}
Over the past decades there has been an increasing recognition of the need to promote dialogue between science and society. Often this takes the form of formal processes, such as citizen's juries, that are designed to allow the public to contribute their views on particular scientific research areas. But there are also many less formal mechanisms that promote a dialogue between science and society. This editorial considers science festivals and citizen science in this context and argues that we need a greater understanding of the potential impacts of these projects on the individuals involved, both scientists and the public.
\end{abstract}

Since its inception, the Journal of Science Communication has covered a wide range of approaches that encourage both the spread of scientific information into the wider society and greater dialogue between scientists and the many and varied publics interested in their research. In the very first editorial published in JCOM, Greco (2002) describes science as a hegemony transforming society through rapid innovation without much thought to society [1]. But Greco also notes that this situation was changing to one where "any real decisions about scientists' work are taken increasingly by the scientific community together with other social groups and, essentially, with society itself."

Since the publication of Greco's editorial there has certainly been a growing emphasis worldwide on encouraging dialogue between science and society [2-4]. Such dialogue can take many forms, including formal participatory processes, semi-formal consultations and seemingly random encounters. The purposes of dialogue are also wide ranging, including formal processes such as regulatory decisions (e.g. consultations on the regulation of scientific endeavour), policy direction (e.g. on research priorities) or at a more individual level scientists engaging with stakeholders to shape research directions as well as small size, semi-formal processes such as discussion games which may not feed directly into participatory processes but can be effective in engaging public audiences in discussion [5]. Dialogue also occurs in many different spaces, both intentionally and unintentionally. Unexpected and unintentional discussion may not feed directly into science policy, governance or research design, and may not use the structured formats of many formal and semi-formal approaches, but it can have profound impacts on those involved, both the public and the scientists.

The commentaries in this issue explore one setting where unexpected dialogue may take place and which seems to be growing in popularity: the science festival. This series of commentaries explores both the trends in science festivals in particular regions, and 
the experience of festival organisers in specific locations. It provides interesting insights into the rationale(s) for science festivals and the experience of the public who engage with them.

Citizen science projects can also provide an opportunity for dialogue, though clearly not all projects seek to do this. Although there are long established citizen science projects, such as the Audubon Bird Count in the U.S.A., little is known about the extent and ways that these projects increase public engagement with science. For this reason, and to stimulate further thinking and discussion in this area, JCOM has announced a call for papers on citizen science that will form the basis for a special issue in 2015. This call invites papers that explore these issues to further our understanding of the potential role of citizen science within the broad field of science communication and public engagement. The full call can be accessed at: http://jcom.sissa.it/call-for-papers-2013-citizen-science and papers should be submitted by $\mathbf{1}^{\text {st }}$ May 2015.

Smaller scale and sometimes serendipitous encounters have the potential to reach many more people than formal public consultation and dialogue initiatives could hope to reach, yet relatively little is known about the impact of these encounters on the individuals involved or on the relationships they create between science and society. Many questions arise, such as: who participates in these encounters and why? We might expect that they largely reach people with a pre-existing interest in science as Crettaz von Roten argues [6], but as Ellen Dowell suggests, placing science in unexpected venues may reach new audiences [7]. There is also plenty of scope to further our understanding of the impacts of these small scale dialogue opportunities on participants, both the public and scientists. This editorial outlined two areas for informal dialogue - science festivals and citizen science. Many other opportunities for face to face encounters exist, from Science Cafes to post-show theatre discussions (see for example: http://chimeranetwork.org) and even the historic staple in the scientists cupboard, the public lecture. The challenge is to articulate a framework that would facilitate rigorous exploration of the impacts of these widely varying encounters between science and society and enabling a better understanding of the ways that they contribute to science communication.

\section{References}

[1] P. Greco (2002), "Communicating in the post-academic era of science" JCOM 01(01): E.

[2] The MASIS Report (2009), Challenging Futures of Science and Society: Emerging trends and Cutting-edge issues, http://ec.europa.eu/research/science-society/document_library/hpdf_06/ the-masis-report_en.pdf.

[3] OECD (2012), Global Science Forum, http://www.oecd.org/science/sci-tech/brochure\%20OECD\%203_09_2012\%20BAT.pdf.

[4] T. Yamaguchi, K. Cronin and D. Macer (2012), "The ethical and social imperatives of dialogue for public engagement in technoscience: trends in Asia-Pacific governance", Ethics in Science and Environmental Politics 12: 53-65.

[5] A. Bandelli (2010), "Engagement tools for scientific governance", JCOM 9(2): C01. 
[6] F. Crettaz von Roten (2011), "In search of a new public for scientific exhibitions or festivals: the lead of casual visitors", JCOM 10(1): A2.

[7] Science Communication Unit, University of the West of England, Bristol (2013), "Science for Environment Policy In-depth Report: Environmental Citizen Science. Report produced for the European Commission DG Environment”, http://ec.europa.eu/science-environment-policy.

[8] E. Dowell (2014), "Einstein's Garden 2009-2014: unexpected encounters with science”, JCOM 13(04): C06.

\section{Author}

Dr. Emma Weitkamp is an Associate Professor in Science Communication at the University of the West of England, Bristol where she teaches on an MSc in Science Communication and provides training in science communication for practitioners and $\mathrm{Ph} . \mathrm{D}$. students. Emma is also Editor in Chief of JCOM. E-mail: Emma.Weitkamp@uwe.ac.uk.

How TO CITE: E. Weitkamp, "Exploring serendipitous dialogue", JCOM 13(04)(2014)E. 